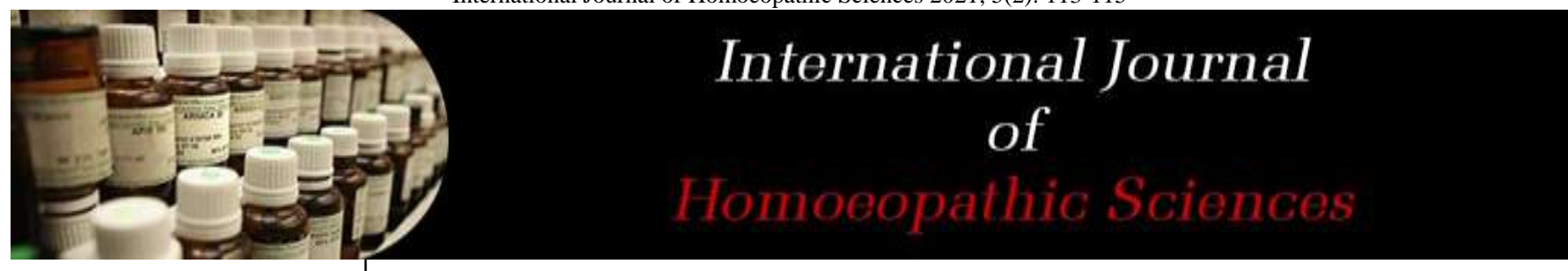

E-ISSN: 2616-4493 P-ISSN: 2616-4485 www.homoeopathicjournal.com IJHS 2021; 5(2): 113-115

Received: 25-01-2021

Accepted: 28-02-2021

Dr. Vaishali Janardhan Ovandkar

MD Hom. Part 2nd Department of HMM GMHMC, Shelgaon, Jalna, Maharashtra, India
Corresponding Author: Dr. Vaishali Janardhan Ovandkar

MD Hom. Part 2nd Department of HMM GMHMC, Shelgaon, Jalna, Maharashtra, India

\section{Allergic rhinitis in children and homoeopathic management}

\author{
Dr. Vaishali Janardhan Ovandkar \\ DOI: https://doi.org/10.33545/26164485.2021.v5.i2b.372
}

\begin{abstract}
In children allergic rhinitis is most commonly diagnosed health disorders. 20 percent of children are affected with AR. Boys are more affected with allergic rhinitis than girls. The median age of onset of allergic rhinitis seen in 10 years old children, children affected with allergic rhinitis equally in number before and after 10 year old. Most of symptoms starts about 2 or 3 years of age. Commonly it is called hay fever. Allergic rhinitis symptoms leads to some effect on a child's health, behavior and ability to learn. Those cases of allergic rhinitis not treated well they lead to a host of other serious conditions, including asthma, recurrent middle-ear infections, sinusitis, sleep disorders and chronic cough. House dust mites, pollen from trees and grasses, cats, dogs, milk and eggs are the most commonly found allergens.

Allergy can be either due to genetic predisposition or external agents. When it is due to genetic predisposition, then it is called as atopy. Allergies like eczema, asthma and hay fever are seen to be familial. Atopy has now become common but its reason is not identified. Allergy is due to increased or change in response of immune system to external agents. Conditions like eczema, allergic asthma, urticaria, hay fever and perennial rhinitis are due to external agent or "allergen". Pollen from trees and grasses, house dust mites, cats, dogs, milk and eggs are most common allergens.

Defination: Allergic rhinitis is characterized by frequent sneezing, nasal fluid secretions, nasal passages obstruction, conjunctival, pharyngeal, nasal itching and lacrimation, all these symptoms occurring in a temporal relationship to exposure of allergen.
\end{abstract}

Keywords: Allergic rhinitis, allergies, atopy, hay fever, hypersensitivity

\section{Introduction}

Allergic rhinitis is commonly seasonal due to elicitation by airborne pollens, it can also be perennial due to chronic exposure. In atopc disorders commenest clinical manifestation is allergic rhinitis.

This state of allergy shows a strong familial predisposition and individuals with this allergic or atopic syndrome may present in early life with infantile eczema and later develop allergic rhinitis, asthma and specific food allergies. It is more common in metropolitan areas compared to rural areas. This is because of increased pollution due to rapidly developed new industries.

there is sleep disturbance, fatigue, depressed mood and cognitive function compromise that impairs quality of life and productivitydue to allergic rhinitis.

As Homoeopathy is a system of medicine which works on inspiring the humoral or the immune mechanism of the body from its latent or overt reaction, it is hence the best form of medicine to treat any allergy. Here the cure is obtained by constitutional treatment.

The constitution depends on early environmental factors, right from the time of conception, acting on the hereditary plan of organization as determined the genes. so individual illness cured if only we can clearly understand the constitution.

The constitutional medicine has a ability to correct the tendencies and abnormal behaviors and reactions to the stress of environment.

\section{a) Aetiology}

Allergic rhinitis generally occurs in atopic individuals who have family history of a similar or related symptom complex and a personal history of collateral allergy presented as eczematous dermatitis, urticaria and/or asthma.

Domestic allergens as mites, domestic animals, insects or of plant origin, common outdoor allergens include pollens and mouldsm, occupational triggers as latex, tobacco smoke, automobile exhaust are triggering factors. 
pollen, House dust, insecticides, animal dander, moulds found on decaying vegetables, feathers, face powders, cockroach, house fly $\&$ butterfly are the commonly found nasal allerges.

Perennial allergic rhinitis occurs due to allergens that are present during the year, including desquamating epithelium in animal dander, cockroach-derived proteins, mold spores, or dust, which has mites such as Dermatophagoides farinae and D. pteronyssinus.

\section{b) Pathophysiology}

In allergic rhinitis there is pale and boggy nasal mucosa, the conjunctiva is congested and edematous, and the pharynx generally unremarkable. There is secondary infections of the sinuses and middle ear respectively due to Swelling of the turbinate and mucous membranes with obstruction of the sinus Ostia and Eustachian tubes. The starting event occurs between intraepithelial mast cells and the allergen, which later proceeds to involve deeper perivenular mast cells, both of which are sensitized with specific IgE. During the symptomatic season when the mucosae are swollen and inflammed, there is enhanced adverse reactivity to the seasonal pollen. Biopsy specimens of nasal mucosa during seasonal rhinitis show sub mucosal edema with infiltration by eosinophils, along with some basophiles and neutrophils. In sensitive individuals, the first appearance of allergenic agent into the nose is presented with sneezing, stuffiness and discharge. The secreted fluid contains histamine, PGD2, and leukotrienes. The mediators through IgE-dependent reactions that are capable of producing tissue edema and eosinophilic infiltration which are generate and release from the mast cells of the nasal mucosa and submucosa.

\section{C) Clinical features}

Moderate to severe inflammation of serous \& mucous membrane. Nasal mucosa is pale \& boggy. Conjunctiva is congested \& edematous. Swelling of turbinate \& mucous membranes.

Frequent sneezing, Nasal Stuffiness, Profuse watery nasal discharge, Obstruction of nasal passage, Conjunctival itching, Watering of the eyes. Burning \& smarting pain in nose \& eyes.

\section{d) Diagnosis}

1. The diagnosis of seasonal allergic rhinitis depends largely on an accurate history of occurrence coincident with the pollination of the offending weeds, grasses, trees.

2. The continuous character of perennial allergic rhinitis due to contamination of the home or place of work makes historic analysis difficult, but there may be variability in symptoms that can be related to exposure to animal dander, dust mite, cockroach allergens, fungal spores, or work-related allergens such as latex.

3. Nasal secretions of allergic patients are abundant in eosinophils, and modest peripheral eosinophilia is a common feature. Local or systemic neutrophilia suggests infection.

4. Total serum IgE is frequently increased, but the demonstration of immunologic specificity for $\operatorname{IgE}$ is important to an etiologic diagnosis.

\section{Prevention}

Avoidance of exposure to the known allergen is the most effective tool of controlling allergic diseases. E.g. Removal of pets from the home to avoid animal products, utilization of air-filtration devices to minimize the concentrations of airborne pollens, elimination of cockroach-derived proteins by chemical destruction of the pest may be necessary. use of plastic lined covers for mattresses, pillows, and comforters; using a filter-equipped vacuum cleaner are helpful in contruling dust mites by avoiding allergen.

\section{Treatment}

Allergic diseases are the outer reflection of the internal problem. So, we need to increase the immunity of the patient and this can be strengthened by homeopathic medicines.

Homeopathic medicine stimulates the body's own defence system to fight with exposure to allergens, than suppressing the allergic symptoms. When we take homeopathic medicine before the start of the hay fever season can protect the patient through the whole season, reducing the need for antihistamines and they are more effective.

Some of the constitutional medicines indicated for allergic rhinitis in children are -

1. Pulsatilla: Repeated attacks of coryza with sneezing \& stuffing up of the nose, fever and sweating. Considerable watery discharge with sneezing in evening, morning stuffing up of the nose with thick yellow, green discharge. Pulsatilla is suitable to chronic Catarrh with bad smell. Associated with loss of smell \& taste. Amelioration to open air. Aggravation in warm room. The child is nervous, timid, yielding.

2. Arsenicum album: There is burning, watery, runny nose with a stuffy, tickling feeling during allergy attacks. Commonly there is Swelling below the eyes and a wheezy cough present. The person may feel chilly, restless, anxious, and is often very tired. The arsenic child is always chilly, always sneezing from every change in the weather. Less in cold damp weather, Hoarseness and sleeplessness with swollen nose, stoppage of nose with copious discharge of watery mucus and burning in the nose. Amelioration warmth. Generally aggrevation from cold.

3. Chamomilla: Coryza first dry and obstructed, then there is scanty moderately acrid discharge, irritation to sneeze with crawling, dry heat; hoarseness, produced by tenacious mucus in larynx \& trachea. Coryza with inability to sleep. Sensitive to all smells. The child is very sensitive, cross, ugly, spiteful snappish very irritable, will not answer when spoken to. Sweating about the head, face red $\&$ hot on the one side. Chilly patient amelioration from heat.

4. Calcarea Carb: The calc carb children suffer from frequent cold, nose block \& sore throat. The child is chilly with profuse sweating. The child is fat, fair \& flabby with deficient bones. Dry nostrils; ulcerated. There is fetid, yellow discharge offensive odor, stoppage of nose. Takes cold at every charge of weather.

5. Sambugus Nigra: Dry coryza of children. There is numbness sensation in nose with itching on bridge. Congestion with sensation of heaviness in point of nose. Accumulation of thick \& viscid mucus in nostrils with nasal obstruction. Snuffles in children. Child starts up suddenly as if suffocating. 
6. Ammonium Carb: Dry coryza \& stoppage of the nose chiefly at night with danger of suffocation. Cannot breathe through the nose. In daytime burning water runs from the nose and dry coryza at night. Sneezing aggrivates due to least breath of cold air. Constant tingling in nose leads to frequent sneezing.

7. Natrum muriaticum: There is loss of taste and smell with sneezing, watery eyes, clear nasal discharge that resembles egg white. The person may have dark circles under the eyes, be thirsty, feel withdrawn and sad, act irritable.

8. Nux vomica: If the nose is alternately stuffed up and running, this remedy may bring relief. There is teasing cough, a scraped or tickly feeling in the throat, headache. A person often feels impatient, irritable, and chilly.

9. Sabadilla: Catarrhal condition of the nose with constant sneezing. There is sensation of rawness in the nose, burning, stuffing of the nose. First there is thin mucus \& later develop thick mucus. The croyza is ameliorated from inhaling hot air. aggrevated by the odor of flowers. Even after thinking of the fruit and flowers odour makes him sneeze \& increases the flow from the nose.

Some other usful remedies are - Aconitum Napellus, Staphysagria, Hydrastis Canadensis, Ranunculous bulbosus, Allium cepa.

\section{Conclusion}

1. Allergic rhinitis is mostly seen in the age group of $2-10$ years.

2. Males are more affected due to allergic rhinitis compared to females.

3. mainly used remedies in allergic rhinitis are Ars Album, Nux Vom, Pulsatilla, Sulphur, Nat Mur, Kali mur, Silicea, Calc carb, Natrum sulph \& Kali bich.

4. Homoeopathic treatment has a scope in treating Allergic rhinitis because $o$ its holistic and individualistic approach.

\section{References}

1 Longo Fauci, Kasper Hauser, Jamson Loscalzo. Harrison's Principles of Internal Medicine: $18^{\text {th }}$ Edition. Mc Graw Hill Pub. 2, 838

2 Kumar P, Clarke Kumar M. Clarke's Clinical Medicine: $6^{\text {th }}$ Edition: Elsevier Saunders Pub 895.

3 Allen HC. Allen's Keynotes, $10^{\text {th }}$ edition. B. Jain Pub 2005, 252,44,94,21,214,224,5,292,14.

4 Kent JT. Lectures on homoeopathic material medica, $15^{\text {th }}$ impression. B.Jain Pub, 858,149,415, 97,767,804,893,19.

5 Achar's Text Book of Pediatrics $4^{\text {rd }}$ revised edition 2009;257-258.

6 Simson Hall Bernard, Colman H. Diseases of the nose throat \& Ear, E \& S. Living Stone 1959, 45.

7 Dr. Shashi Kant Tiwari. Homoeopathy \& child care B Jain Publishers Pvt Ltd, UK ed. edition 2002, 216.

8 Dr. Mukerji RK. Constitutional and Temperament B Jain Publishers Pvt. Limited 2003, 2.

9 Dr. Dhawale ML. Principles and practice of Homoeopathy. Part-I, Indian Books \& Periodicals Publishers $3^{\text {rd }}$ edition 2000, 24.

10 Homoeopathic therapeutics by Samuel Lilienthal, B
Jain Pub Ltd; 2005, Reprint edition 1992;616:132.

11 Shivaraman P, E.N.T Troubles cured with Homoeopathic Medicines, B Jain Pub Pvt Ltd; $1^{\text {st }}$ edition 2005;236(17):232, 26.

12 Boericke Boriecke's W. New Manual of Homoeopathic Materia Medica with Repertory, 9 $^{\text {th }}$ edition: B. Jain Publishers 2011.

13 Clarke JH, A Dictionary of Practical Materia Medica. New Delhi: B. Jain Publishers Pvt. Ltd 2015.

14 Phatak SR. Materia Medica of Homoeopathic Medicines. New Delhi: B. Jain Publishers Pvt. Ltd. 2007.

15 Dhingra PL. Diseases of ear, nose, throat. 4thed. New Delhi: Elsevier India private Ltd 2004.

16 Chandrika D. Allergic rhinitis in India: an overview. International Journal of Otorhinolaryngology and Head and Neck Surgery 2016.

17 Small P, Kim H. Allergic rhinitis. Allergy, Asthma \& Clinical Immunology 2011;7(S1).

18 Lilienthal S. Homoeopathic Therapeutics, reprint edition B. Jain publishers, New Delhi 2007.

19 Dubey SR, Text Book Of Materia Medica, Books And Allied (P) Ltd. 2002, 329, 49,126,30,279, 8, 378,21.

20 Allergic rhinitis [Internet].En.wikipedia.org. 2021 [cited 1February 2021]. Available from: https://en.wikipedia.org/wiki/Allergic_rhinitis.

21 National Journal of Homoeopathy, www.njhonline.com. 95 ${ }^{\text {th }}$ issue August 2007;9:20. 